\title{
Experimental Testing Of Natural Composite Material (Jute Fiber)
}

\author{
K.Rajasekar \\ Assistant Professor, Department of Mechanical Engineering, Karur College Of Engineering, Karur, \\ Tamilnadu, India.
}

\begin{abstract}
Composite materials combine two distinct materials to obtain enhanced properties. Composite materials are as old as jute natural fiber as reinforcement material with polymer materials matrix. A specimen product of such a composite will be developed through layer by layer method at a certain temperature to suit the processes. The composite will be tested for its mechanical properties using conventional testing machines and the results will be recorded. The campsite will also be analyzed using ANSYS software for its mechanical properties and the result will be compared with the experimental results the resulting properties would help to identify the suitable applications for this composite.
\end{abstract}

\subsection{COMPOSITES MATERIAL}

\section{Introduction}

A Composite Materials is a macroscopic combination of two or more distinct materials, having recognizable interface between them. Properties of Composite materials are very fatigue resistance. Composite materials have medium to low level impact resistance.

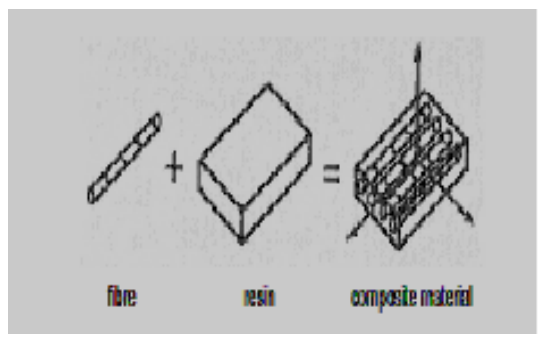

Composite materials have excellent fire resistance as compared with the light alloys with identical thicknesses. However; the smokes emitted from the combustion of certain matrices can be toxic.

\subsection{CLASSIFICATION OF FIBERS}

- Glass Fibers

- Metallic Fibers

- Animal Fibers

- Boron Fibers

- Silicon carbide fibers

- Natural Fibers

\subsection{CARBON FIBRES}

Carbon and graphite have a special place in composite materials options, both being highly superior, high temperature materials with strengths and rigidity that are not affected by temperature up to $2300^{\circ} \mathrm{C}$. This carbon-carbon composite is fabricated through compaction of carbon or multiple impregnations of porous frames with liquid carbonized precursors and subsequent pyrolization. They can also be manufactured through chemical vapor deposition of pyrolytic carbon.

Carbon-carbon composites are not be applied in elevated temperatures, as many composites have proved to be far superior at these temperatures. However, their capacity to retain their properties at room temperature as well as at temperature in the range of $2400^{\circ} \mathrm{C}$ and their dimensional stability make them the oblivious choice in a garnet of applications related to aeronautics, military, industry and space.

Components, that are exposed to higher temperature and on which the demands for high standard performance are many, are most likely to have carbon-carbon composites used in them. 


\subsection{CERAMICFIBRES}

In comparison to ceramics and even considered on their own merit, glass matrices are found to be more reinforcement-friendly. The various manufacturing methods of polymers can be used for glass matrices. Glasses are meant to improve upon performance of several applications. Glass matrix composite with high strength and modulus can be obtained and they can be maintained up to temperature of the order of $650^{\circ} \mathrm{C}$.

Composites with glass matrices are considered superior in dimensions to polymer or metal system, due to the low thermal expansion behavior. This property allows fabrication of many components in intricate shapes and their tribological characters are considered very special. Since the elastic modulus of glass is far lower than of any prospective reinforcement materials, application of stress usually results in high elasticity modulus fiber that the tensile strength of the composite its considerably enhanced than that of the constituents, which is not case in ceramic matrices.

\subsection{REINFORCEMENTS}

Reinforcements for the composites can be fibers, fabrics particles or whiskers. Fibers are essentially characterized by one very long axis with other two axes either often circular or near circular. Particles have no preferred orientation and so does their shape. Whiskers have a preferred shape but are small both in diameter and length as compared to fibers. Shows types of reinforcements in composites.

Reinforcing constituents in composites, as the word indicates, provide the strength that makes the composite what it is. But they also serve certain additional purposes of heat resistance or conduction, resistance to corrosion and provide rigidity. Reinforcement can be made to perform all or one of these functions as per the requirements.

A reinforcement that embellishes the matrix strength must be stronger and stiffer than the matrix and capable of changing failure mechanism to the advantage of the composite. This means that the ductility should be minimum or even nil the composite must behave as brittle as possible. Fibers are the important class of reinforcements, as they satisfy the desired conditions and transfer strength to the matrix constituent influencing and enhancing their properties as desired. Glass fibers are the earliest known fibers used to reinforce materials. Ceramic and metal fibers were subsequently found out and put to extensive use, to render composites stiffer more resistant to heat.

Fibers fall short of ideal performance due to several factors. The performance of a fiber composite is judged by its length, shape, and orientation, composition of the fibers and the mechanical properties of the matrix. The orientation of the fiber in the matrix is an indication of the strength of the composite and the strength is greatest along the longitudinal directional of fiber. This doesn't mean the longitudinal fibers can take the same quantum of load irrespective of the direction in which it is applied. Optimum performance from longitudinal fibers can be obtained if the load is applied along its direction. The slightest shift in the angle of loading may drastically reduce the strength of the composite. silica carbide and boron are also exercising the scientific mind due to their applications in advanced composites.

\subsection{NATURAL FIBERS}

First the fiber classification and some general aspects are presented followed by a summary of the most widely applied natural fibers, involving quantities, harvesting methods and properties. A closer look will be given at the manufacturing of traditional natural fiber products as part of the rural industry.

\subsection{GLASS FIBERS}

Over $95 \%$ of the fibers used in reinforced plastics are glass fibers, as they are inexpensive, easy to manufacture and possess high strength and stiffness with respect to the plastics with which they are reinforced. Their low density, resistance to chemicals, insulation capacity are other bonus characteristics, although the one major disadvantage in glass is that it is prone to break when subjected to high tensile stress for a long time.

However, it remains break-resistant at higher stress-levels in shorter time frames. This property mitigates the effective strength of glass especially when glass is expected to sustain loads for many months or years continuously. Period of loading, temperature, moisture and other factors also dictate the tolerance levels of glass fibers and the disadvantage is further compounded by the fact that the brittleness of glass does not make room for prior warning before the catamorphic failure.

But all this can be easily overlooked in view of the fact the wide range of glass fiber variety lend themselves amicably to fabrication processes like matched die-mounding, filament winding lay-up and so on. Glass fibers are available in the form of mates, tapes, cloth, continuous and chopped filaments, roving and yarns. Addition of chemicals to silica sand while making glass yields different types of glasses. 


\subsection{METALS FIBERS}

As reinforcement, metal fibers have many advantages. They are easily produced using several fabrication processes and are more ductile, apart from being not too sensitive to surface damage and possess high strengths and temperature resistance. However, their weight and the tendency to react each other through alloying mechanisms are major disadvantages.

Ceramic fibers improve vastly in performance when a fine metal outline is incorporated with refractory ceramics by improving their thermal shock and impact resistance properties. Metal wires, of the continuous version, also reinforce plastics like polyethylene and epoxy. Such combinations ensure high strength, light weight and good fatigue resistance. Besides, continuous metal fibers are easily handled, unlike glass fibers. Better flexural properties are observed in some metal fibers reinforced plastic composites which also offer improved strength and weight, than glass fibers. However, their poor tolerance of high temperature and the resultant steep variations of thermal expansion coefficient with the resins are a discouragement that limits their their application.

\subsection{ALUMINA FIBERS}

Alumina aluminum oxide fibers, basically developed for use in metal matrices are considered a potential resin-matrix composite reinforcement. It offers good compressive strength rather than tensile strength. It's important property is it's high melting point of about $2000^{\circ} \mathrm{C}$ and the composite can be successfully used at temperature up to about $1000^{\circ} \mathrm{C}$. Magnesium and aluminum matrices frequently use alumina fiber reinforced composites as they do not damage the fiber even in the liquid state.

\subsection{BORON FIBERS}

They are basically composites, in which boron is coated on a substance which forms the substrate, usually made of tungsten. Boron-tungsten fibers are obtained by allowing hot tungsten filament through a mixture of gases. Boron is deposited on tungsten and the process continued until the thickness is achieved. The tungsten however remains constant in its thickness. Properties of boron fibers generally change with the diameter, because of the changing ratio of boron to tungsten and the surface defects that change according to size. However, they are known for their remarkable stiffness and strength. Their strengths often compare with those of glass fibers, but their tensile modulus is high, almost four to five that of glass. Boron coated carbons are much cheaper to make than boron tungsten fiber. But is low modulus of elasticity often works against it.

\subsection{SILICON CARBIDE FIBERS}

Silicon carbide can be coated over a few metals and their room temperature tensile strengths and tensile module are like those boron-tungsten. The advantages of silicon carbide-tungsten are several and are more desirable than uncoated boron tungsten fibers. Elevated temperature performance and the fact that they reported only a $35 \%$ loss of strength at $1350^{\circ} \mathrm{C}$ are their best qualities. Silicon carbide-tungsten and silicon carbidecarbon have both been seen to have very high stress-rupture strength at $1100^{\circ} \mathrm{C}$ and $1300^{\circ} \mathrm{C}$. Uncoated borontungsten fibers do not react with molten aluminum, unlike uncoated boron and they also withstand high temperatures used in hot-press titanium matrices.

However, Silicon carbide-tungsten fibers are dense compared to boron-tungsten fibers of the same diameters. They are prone to surface damage and need careful, delicate handling, especially during fabrication of the composite. Further, above $930^{\circ} \mathrm{C}$ weakening reactions occur between tungsten and silicon carbide, making it different to maintain balance in high-temperature matrix formations. Silicon carbide on carbon substrates have several advantages, viz. no reaction at high temperature, being lighter than silicon carbide tungsten and possessing tensile strengths and modulus that is are often better than those of silicon carbidetungsten and boron fibers.

\subsection{ARAMID FIBERS}

Aramid fibers are made aromatic polyamides which are long polymeric chains and aromatic rings. They are structures in which six carbon slatoms are bonded to each other and to combinations of hydrogen atoms. In aramid fibers, these rings occur and reoccur to form the fibers. They were initially used to reinforce automobile tires. Since then, they have also found other uses like bullet proof vests. As high strength applications, their use in power boats is not uncommon. Aramids have high tensile strength, high modulus and low weight.

Impact-resistant structures can be produced from aramids. The density of aramid fibers is less than that of glass and graphite fibers. They are fire resistant apart from being high-temperature resistant and unaffected by organic solvents fuels. But their resistance in acid and alkaline media is poor. They are supple and allow themselves to be woven into matrices by simple processes. Aramid fibers have a negative coefficient of thermal expansion in the fiber direction and failure of Aramid fibers is unique. When they fail, the fibers break into 
small fibers, which are like fibers within the fibers. This unique failure mechanism is responsible for high strength.

\section{Natural Fibers}

First the fiber classification and some general aspects are presented followed by a summary of the most widely applied natural fibers, involving quantities, harvesting methods and properties. A closer look will be given at the manufacturing of traditional natural fiber products as part of the rural industry.

\subsection{NATURAL FIBRE CLASSIFICATIONS}

Natural fibers, often referred to as vegetable fibers, are extracted from plants and are classified into three categories, depending on the part of the plant they are extracted from. Fruit fibres are extracted from the fruits of the plant, they are light and hairy, and allow the wind to carry the seeds. Bast fibers are found in the stems of the plant providing the plant its strength. Usually they run across the entire length of the stem and are therefore very long.

Fibers extracted from the leaves are rough and sturdy and form part of the plant's transportation system, they are called leaf fibers. When determining the properties of natural fibers, one has to keep in mind that one is dealing with natural products with properties that are strongly influenced by their growing Environment. Temperature, humidity, the composition of the soil and the air all effect the height of the plant, strength of its fibres, density, etc. Also the way the plants are harvested and processed results in a variation of properties.

Jute fibers are extracted from the ribbon of the stem. When harvested the plants are cut near the ground with a sickle shaped knife. The small fibers, $5 \mathrm{~mm}$, are obtained by successively retting in water, see figure 3.3 , beating, stripping the fiber from the core and drying. Due to its short fibre length, jute is the weakest stem fiber, although it withstands rotting very easily. It is used as packaging material (bags), carpet backing, ropes, yarns and wall decoration.

\begin{tabular}{|l||c||c||c|}
\hline \multicolumn{1}{|c|}{ Property } & Jute & Sisal & Coir \\
\hline \hline Width (mm ) & - & $50-200$ & $100-450$ \\
\hline \hline Density (gms./cc) & 1.3 & 1.45 & 1.15 \\
\hline $\begin{array}{l}\text { Volume Resistivity at } \\
100 \mathrm{~V}\end{array}$ & - & $0.4-0.5$ & $9-14$ \\
\hline $\begin{array}{l}\text { Micro-Febrile Angle } \\
\text { (degree) }\end{array}$ & 8.1 & $10-22$ & $30-49$ \\
\hline \hline $\begin{array}{l}\text { Cellulose/Lignin } \\
\text { Content }\end{array}$ & $61 / 12$ & $67 / 12$ & $43 / 45$ \\
\hline \hline $\begin{array}{l}\text { Elastic Modulus } \\
\text { (GN/m2) }\end{array}$ & - & $9-16$ & $4-6$ \\
\hline \hline Tenacity (MN/m2) & $440-533$ & $568-640$ & $131-175$ \\
\hline \hline Elongation (\%) & $1-1.2$ & $3-7$ & $15-40$ \\
\hline \hline
\end{tabular}

\subsection{JUTE FIBER}

Jute is a best fiber obtained from inner bast tissues of the plant stem. The fibers are bound together by gummy materials (pectinous substances) which keep the fiber bundles cemented with non - fibrous tissues of jute bark. These encircling soft tissues must be softened, dissolved and washed away so that the fiber can be obtained from the stem. This is done by steeping the stems in water and is known as retting.

The optimum water temperature for retting is $80^{\circ} \mathrm{F}$. Micro - organisms (mainly bacillus bacteria) decompose upon temperatures and the type of water used. It has been found that the presence of higher the tenacity of fiber 


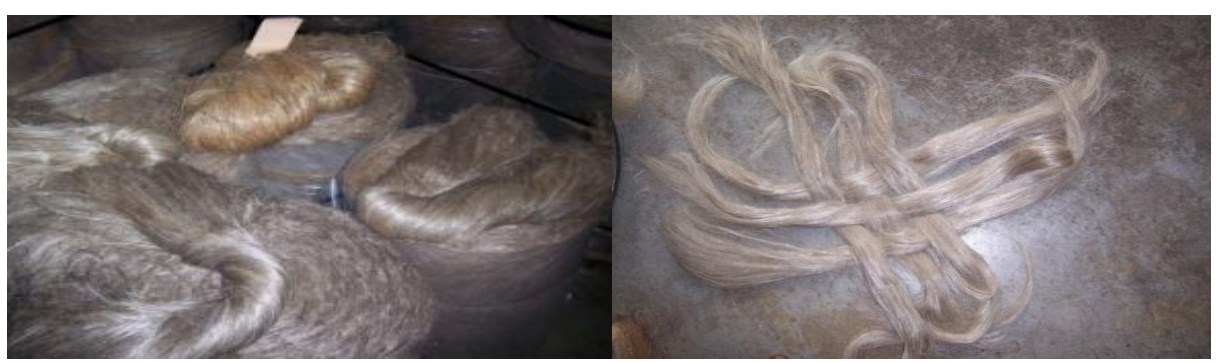

In this research, a unidirectional type of fabric weave having a count of $20 \times 12$ (for yarns of $245-302$ Tex) is investigated. $20 \times 12$ indicates 20 in number larger yarns in the wrap direction and 12 in number smaller yarns in the weft direction per inch are used. Jute fiber is $100 \%$ biodegradable and recyclable and thus environmentally friendly. It is a natural fiber with golden and silky shine and hence called The Golden Fibre.It is the cheapest vegetable fiber procured from the best or skin of the plant's stem.

\begin{tabular}{|c|c|c|c|}
\hline $\begin{array}{c}\text { Typical } \\
\text { Properties }\end{array}$ & $\begin{array}{c}\text { High } \\
\text { Strength }\end{array}$ & $\begin{array}{c}\text { High } \\
\text { Modulus }\end{array}$ & $\begin{array}{c}\text { Ultra-High } \\
\text { Modulus }\end{array}$ \\
\hline $\begin{array}{c}\text { Density } \\
\left(\mathrm{g} / \mathrm{cm}^{3}\right)\end{array}$ & $\mathbf{1 . 8}$ & $\mathbf{1 . 9}$ & $\mathbf{2 . 0}-\mathbf{2 . 1}$ \\
\hline $\begin{array}{c}\text { Young's } \\
\text { Modulus } \\
\text { (GPa) }\end{array}$ & $\mathbf{2 3 0}$ & $\mathbf{3 7 0}$ & $\mathbf{5 2 0}-\mathbf{6 2 0}$ \\
\hline $\begin{array}{c}\text { Tensile } \\
\text { Strength } \\
\text { (GPa) }\end{array}$ & $\mathbf{2 . 4 8}$ & $\mathbf{1 . 7 9}$ & $\mathbf{1 . 0 3 - 1 . 3 1}$ \\
\hline $\begin{array}{c}\text { Tensile } \\
\text { Elongation } \\
(\%)\end{array}$ & $\mathbf{1 . 1}$ & $\mathbf{0 . 5}$ & $\mathbf{0 . 2}$ \\
\hline
\end{tabular}

It is the second most important vegetable fibre after cotton, in terms of usage, global consumption, production, and availability.

It has high tensile strength, low extensibility, and ensures better breath ability of fabrics. Therefore, jute is very suitable in agricultural commodity bulk packaging. It helps to make best quality Industrial yarn, fabric, net, and sacks. It is one of the most versatile natural fibres that have been used in raw materials for packaging, textiles, non-textile, construction, and agricultural sectors.

Bulking of yarn results in a reduced breaking tenacity and an increased breaking extensibility when blended as a ternary blend. Unlike the hemp fibre, jute is not a form of cannabis.

The best source of jute in the world is the Bengal Delta Plain in the Ganges Delta, most of which is occupied by Bangladesh.

Advantages of jute include good insulating and antistatic properties, as well as having low thermal conductivity and moderate moisture regain. Other advantages of jute include acoustic insulating properties and manufacture with no skin irritations.

Jute has the ability to be blended with other fibres, both synthetic and natural, and accepts cellulose dye classes such as natural, basic, vat, sulfur, reactive, and pigment dyes.

As the demand for natural comfort fibres increases, the demand for jute and other natural fibres that can be blended with cotton will increase. To meet this demand, some manufactures in the natural fibre industry plan to modernize processing with the Rieter's Elitex system.

The resulting jute/cotton yarns will produce fabrics with a reduced cost of wet processing treatments.

Jute can also be blended with wool. By treating jute with caustic soda, crimp, softness, pliability, and appearance is improved, aiding in its ability to be spun with wool. Liquid ammonia has a similar effect on jute, as well as the added characteristic of improving flame resistance when treated with flame proofing agents.

Disadvantages include poor drapability and crease resistance, brittleness, fibre shedding, and yellowing in sunlight. However, preparation of fabrics with castor oil lubricants result in less yellowing and less fabric weight loss, as well as increased dyeing brilliance.

Jute has a decreased strength when wet, and also becomes subject to microbial attack in humid climates. Jute can be processed with an enzyme in order to reduce some of its brittleness and stiffness. Once treated with an enzyme,

Jute shows an affinity to readily accept natural dyes, which can be made from marigold flower extract. 
In one attempt to dye jute fabric with this extract, bleached fabric was mordanted with ferrous sulphate, increasing the fabric's dye uptake value. Jute also responds well to reactive dyeing.

This process is used for bright and fast coloured value-added diversified products made from jute.

\section{Manufacturing Methods}

- Manual lay-up, Wet lay-up

- Manual lay-up, Prepreg lay-up

- Bag Molding

- Autoclave processing

- Filament winding

- Resin transfer molding

- Thermoplastic composites

\subsection{WET/HAND LAY-UP METHOD}

Resins are impregnated by hand into fibers which are in the form of woven, knitted, stitched or bonded fabrics. This is usually accomplished by rollers or brushes, with an increasing use of nip - roller type impregnators for forcing resin into the fabrics by means of rotating rollers and a bath of resin. Laminates are left to cur under standard atmospheric conditions.

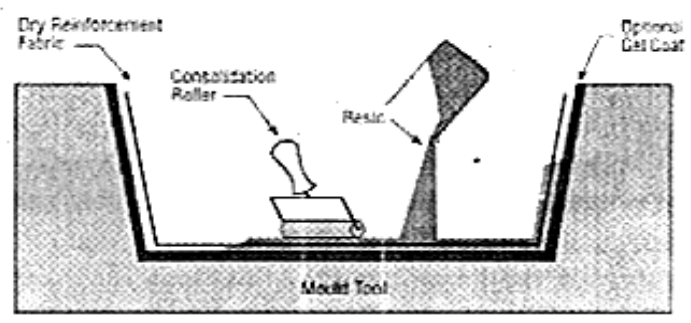

Materials Options:

Resins: Any, e.g. epoxy, polyester, vinyl ester, phenolic.

Fibers: Any, although heavy aramide fabrics can be hard to wet - out by hand.

Cores: any.

\section{Mechanical Testing Of Fibres}

All mechanical tests except impact tests have been carried out on a computer - controlled closed - loop servo - draulic MTS - 810, having a maximum capacity of 10 metric ton. For the tests, the 1 metric ton range is used. Load, displacement and liner strain are measured using a load cell, linearly variable differential transformer (LVDT) and clip - on type extensometer, respectively. The longitudinal and lateral strains used to calculate the Poisson's ratio are measured by strain gauges mounted on the specimen in conjunction with strain indicator B and $\mathrm{K}$ type

1526. PC based Test work - II, with application software was employed for composite testing.

Analysis of the output files was by MAT LAB software for post - processing and graphics. A minimum of five composite samples were tested to account for statistical scatter to arrive at mean values. All the tests are carried out at room temperature.

\subsection{TENSILE TEST}

Tests on yarn and fabric (count $20 \times 12$ ) having a gauge length of $200 \mathrm{~mm}$ are carried out at a cross head speed of $1.3 \mathrm{~mm} / \mathrm{min}$; the tensile strength and modulus are thus obtained. The cross - sectional area of yarn is assumed to be circular and with the help of a profile projector, the diameter of the slightly stretched yarn is measured. The cross - sectional area of fabric is obtained by multiplying the number of yarns per inch of fabric and average cross - sectional area of each yarn in the fabric.

Tests on polyester resin and composite specimens are carried out to determine tensile strength, modulus of elasticity and Poisson's ratio.

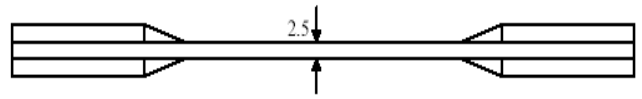

Tensile: 5 specimens tested on a Wick machine at room temperature, with a load cell of $250 \mathrm{kN}$, following normative ASTM D3039 (D638 for test on resin) 


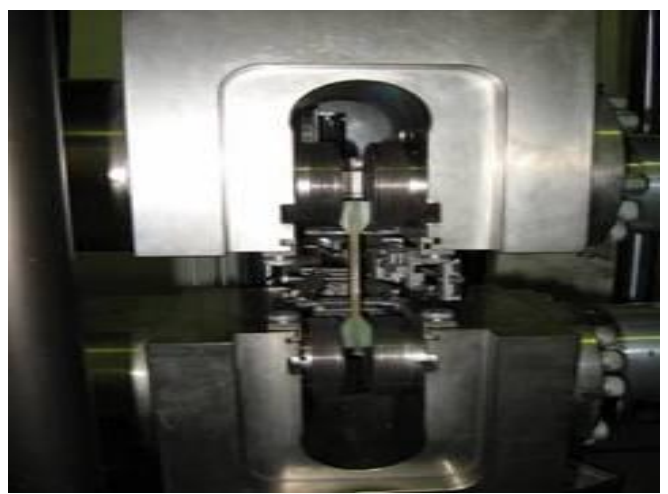

\subsection{COMPRESSION TEST}

Tests are carried out on polyester resin and composite specimens to determine compressive strength, modulus of elasticity and Poisson's ratio. The specimens are and loaded, leaving an unsupported length as the test section.

\subsection{IMPACT TEST}

Square Specimens 100x 100 Mm Have Been Utilized For the Impact Test (For Each Energy Level) Bounded With A Clamping (ASTM D5628-96, ASTM D5428-98 ${ }^{\text {th }}$. The hemispherical head impacted has a mass of $3.966 \mathrm{Kg}$ and a diameter of $12.7 \mathrm{~mm}$

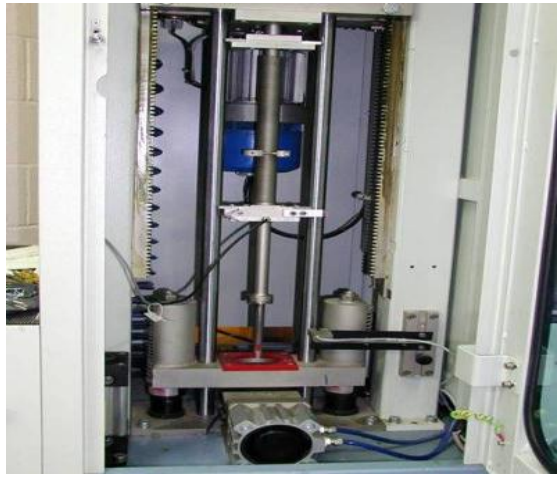

\subsection{FLEXURAL TEST}

The polyester resin and composite specimens have a length / thickness (L/d) ratio of 32.1. The flexural test is initiated by applying the load perpendicular to the fiber direction. For composite specimens a three - point bend test and for resin specimens a four - point bend test are adopted. The relations for flexural strengths and module are $\sigma=3 \mathrm{FL} / 2 \mathrm{bd}^{2} \mathrm{Mpa}, \mathrm{E}_{\mathrm{b}}=\mathrm{L}^{3} \mathrm{~m} / 4 \mathrm{bd} 3 \mathrm{GPa}, \sigma=\mathrm{FL} / \mathrm{bd}^{2} \mathrm{Mpa}$, and $\mathrm{E}_{\mathrm{b}}=0.21 \mathrm{~L}^{3} \mathrm{~m} / \mathrm{bd}^{3}$, respectively, where $\mathrm{F}=$ load, $\mathrm{N} ; \mathrm{L}=$ span length, $\mathrm{mm}$; the distance between inner and outer loading point Is L/3 and the load span is also equal to L/3 as per ASTM -D 790 standard; $m=$ slope of the load - deflection curve at a linear region.

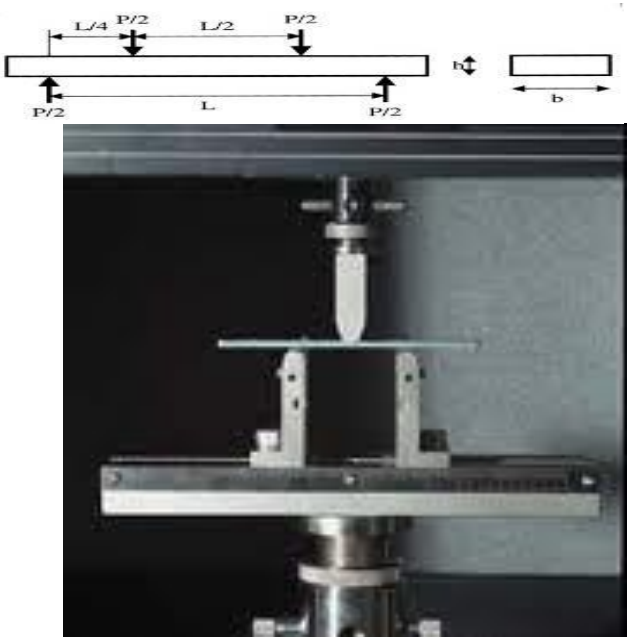




\section{Preparation Method:}

First to take the resins are (hardener and softener) mixing uniformly. They are mixing ratios 1:3 only.

Next to take the natural fibers as per required size cut and the resins both are mixed wall. Mixed materials are (not dry or wet stage) in between the solidification.

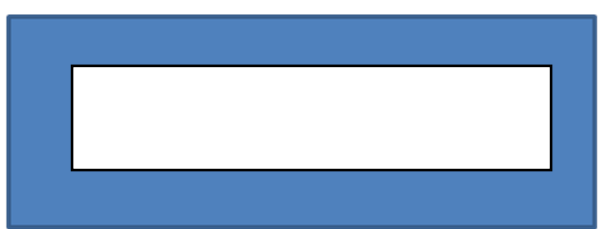

MILD STEEL DIE

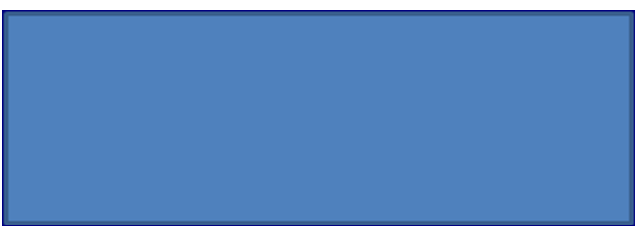

MILD STEEL BASE PLATE

Next M.S.Mould die was prepared. (300mmx $25 \mathrm{mmx} 10 \mathrm{~mm}$ ). Die material is mild steel only. it is suitable for all applications. Now the mould box was ready. Before poured the materials to apply the polythene paper cover provided all the areas, due to surface finish good. Next already prepared the mixed material poured in to the mould cavity, now the die is filled required shape form. After the mould should not enter all the places uniform mixing materials. So just put into the heater or furnace heated up to 60 degree c maintained 10 to 15 minutes. At the time of heating, material and resins bonding each other remove the blow holes or avoid the blow holes and also uniform flow ability. Improve the stiffness, and strength of the composite beam.

After completely the mould specimen was ready. The specimen removed from the mould cavity very carefully. After removing the specimen still 3 to 4 hours maintained the atmosphere (air) cooling done completely.

Again the specimen was put in the same mould cavity. Apply the force to gradually compress the Specimen. In this condition still maintained the load up to 8 hours. (Normally) After 8 hours was completed, the specimen was ready.

\subsection{METHODS OF ANALYSIS}

\section{6. Analysis Of Beam}

A mild steel cantilever beam of size $300 \times 50 \times 10(\mathrm{~mm})$ is considered as a main system is shown in. the absorber system is attached on the beam at different locations. Provides the geometric and material properties of the beam.

\section{COMPOSITESPECIMEN}

Beams studied in this paper are long, thin, cantilever beams. Figure, below, shows such a beam. One end of the beam is fixed, while the other end is free. The origin of the coordinate axis is at the fixed end, point A.A typical beam, used in this study, is $\mathrm{L}=300 \mathrm{~mm}$ long, $\mathrm{W}=5 \mathrm{~mm}$ wide and $\mathrm{t}=2.5 \mathrm{~mm}$ thick.

\begin{tabular}{|l|c|}
\hline \multicolumn{1}{|c|}{ Property } & Value \\
\hline Length (l) & $300 \mathrm{~mm}$ \\
\hline Width (w) & $50 \mathrm{~mm}$ \\
\hline Thickness (t) & $10 \mathrm{~mm}$ \\
\hline Cross sectional area (A) & $500 \mathrm{~mm} 2$ \\
\hline Moment of inertia (I) & $4166.6 \mathrm{~mm} 4$ \\
\hline
\end{tabular}




\section{Methodology}

The objective of the project is to be fabricating a new composite and analysis its properties. The methodology includes the following aspects.

A specimen product of the composite will be fabricated combining jute a natural fiber with a polymer resin a matrix through layer by layer method at a suitable temperature for bonding of the materials and curing process to take place.

The fabricated specimen composite will be tested for its mechanical properties using conventional Testing machines and the values recorded. The specimen will also be analyzed using ANSYS software for its mechanical properties and the results are recorded and compared with the experimental results. The results of the analysis will be discussed to identify its properties and find suitable applications.

\section{Conclusion:}

In the current work, jute fiber reinforced polymer resin a matrix composites were manufacturing using layer by layer methods. The specimen will be testing machines and results are analyzed by ANSYS software

\section{References}

[1]. Perlman Hob, Ismail H, Bahrain A. A comparison of the mechanical properties of rice husk powder filed polypropylene composites with talc filled polypropylene composites. Poly test 2002; 21 (7): $833-9$.

[2]. Yang he, Kim hajj, lee be, Hwang Ts, water absorption behavior and mechanical properties of lignocelluloses' filler - polyolefin bio composites. Comp strict 2006; 72: 429 - 37.

[3]. Sui G X, Yu T X, Kim J K, Zhou B L. Mechanical behavior and failure modes of aluminum/bamboo sandwich plates under quasistastic loading

[j]. J. Mater sci, 2000, 35: 1445 - 1452 .

[4]. Karakas A, Chatham Ss. Modal JM, Chandra Mechanical properties wood - fiber reinforced polypropylene composites. Comp a 2007; 38: $227-33$.

[5]. Hamada h. Lkuta n. Nishida n. Maekaewa z. Effect to interfacial silane network structure on interfacial strength in glass fiber composites. Composites 1994; 25: 512.

[6]. Eichhorn Sj, Baillie Ca, Zaferiopoulos N, Akimbo Ly, Ansell Mp, Dufresne A, Et.Al. Current international research into cellulosic fibers and composites. J mater sci 2001; 36:2107.

[7]. Dwain, M.A., hu, b., O’Donnell, A., H.W., wool, R.P., 2004. All natural composite sandwich beams for structural applications. Compos.struct63, $147-157$.

[8]. John, k., Venkata Naidu, S., 2004a. Sisal fiber / glass fiber hybrid composites: impact and compressive properties. J. Reins. Plats. Compos. 23(12), $1253-1258$.

[9]. Bedzin AK, Gassan J. Composites reinforced with cellulose based fibers. Prog polyp sic 1999; $24(2): 221-74$.

[10]. Eichhorn Sj, Baillie Ca, Zafeiropoulos N, Mwaikambo Ly, Ansell Mp, Dufresne A, Et. Al review current international research into cellulosic fibers and composites. J. Mater sci 2001; $36: 2107-31$.

[11]. Doan T - T Loan, Madder E. Performance of jute fiber reinforced polypropylene. In: $7^{\text {th }}$ international ark - TV conference, September 28-29; 2004.Baden - Baden.

[12]. Wampum, P Ivens J, Verbose I. Natural fibers: can they replace glass in fiber reinforced plastics? Compos sic techno 2003; 63: $1259-1264$.

[13]. Serkin V, Zafeiropoulos Ne, Simon F, panayiotou c. A study of the effect of acetylation and propionylation surface treatment on natural fibers. Composites part a 2005; 36: $1110-8$.

[14]. Shah A.N. Lacked sc. Mechanical properties of jute reinforced plastics. Fiber science and technology 1981; 15:41 - 46. 